\title{
Induction of small E.M.F from A.C ripples obtained from a rectifier
}

\author{
Parantap Nandi \\ Institution: IIE (West Bengal University of Technology)
}

\begin{abstract}
A half wave rectifier utilizes only one half cycle of the A.C signal. Since the circuit can not be $100 \%$ D.C the output contains ripple. These A.C components when fed to a transformer may give an A.C voltage at the transformer output. But this voltage varies with load at the output i.e. it depends on whether the load is linear (resistor), non linear (diode), capacitive or inductive etc. Also the output voltage varies if a capacitor is connected in parallel to the resistance which is connected in series with the half wave rectifier. An incandescent lamp having a tungsten filament is used to control current. An amplifier constructed using a single transistor was also used to study the relationship between the no load voltage of the transformer and the full load voltage. At $50 \mathrm{~Hz}$ the ripple components in a half wave rectifier are just enough to give about $6 \mathrm{~V}$ amplified output when a $10 \mathrm{~W}$ lamp is used to control D.C current in the circuit (later explained in the diagram). The power consumption in the circuit considering stray losses is about $15 \mathrm{~W}$ which is fairly small.
\end{abstract}

Keywords: - Transformer, transistor, capacitor, rheostat.

\section{INTRODUCTION}

A half wave rectifier is designed using a single diode. It allows current to pass only through a single cycle of A.C. During the other half cycle the diode is reverse biased and therefore blocks current. The circuit does not however guarantee a pure D.C output because the output contains A.C ripple. 100\% filtration can't be achieved. However the ripple may be minimized using an inductor because it passes D.C easier than it does A.C. An ordinary choke only passes D.C and retards A.C. A capacitor only passes the A.C components to the ground. So these components are not of much use.

However if a transformer (also a type of inductor) is used instead of an ordinary choke the ripple may be trapped in the windings and hence it will generate an E.M.F at the secondary. This E.M.F has a small magnitude and can be easily amplified. For his a suitable transistor is required. In absence of amplification, the transformer output voltage can still be used to drive another circuit.

An average transformer is rated at about 30VA and is about $90 \%$ efficient (the efficiency may be greater). But such transformer can not generate an E.M.F about $1 / 3$ of the rated E.M.F unless the primary voltage is reduced by another transformer. But this will require another transformer. So the circuit will become quite expensive. Also power consumption will be more (about 50-60W).

A D.C circuit making use of a half wave rectifier and a control resistance about $10 \mathrm{~W}$ or less can generate a pulsating signal which when fed to the low voltage side of a transformer generates a small voltage about $2 \mathrm{~V}$ at the high voltage side. This is suitable for LED, carbon resistors etc. If we assume the efficiency to be $70 \%$ the power consumed is only about $20 \mathrm{~W}$. If the control resistance is replaced by a capacitor of about $10 \mu \mathrm{F}$ a voltage of $.1 \mathrm{~V}$ will still exist at the H.V side of the transformer. The capacitor is not ideal so it possesses leakage reactance. This is he reason for the induction of E.M.F. But the generated E.M.F drops when a load is connected. The terminal voltage is least when the base-emitter of a transistor with the collector open is used as a load. Similarly a capacitor when used as load gives a terminal voltage greater than open circuit voltage.

Apparatus and specifications:

1. Transformer rated $230-12 \mathrm{~V}, 3 \mathrm{~A}$.

2. A diode (Type 40KSR40).

3. Incandescent lamps rated $250 \mathrm{~V} 10 \mathrm{~W}, 15 \mathrm{~W}, 40 \mathrm{~W} \& 100 \mathrm{~W}$.

4. A conventional A.C fan regulator (used as rheostat).

5. Light emitting diode (any color).

6. Aluminium Choke (used in fluorescent tube lights).

7. IN4007 diode.

8. Capacitors with capacitances $474 \mathrm{pF}, 2.5 \mu \mathrm{F}, 10 \mu \mathrm{F}, 22 \mu \mathrm{F}$ having suitable voltage ratings (at least $250 \mathrm{~V}$ ).

9. Carbon resistors.

10. Transistor (Type CL100S). 
Circuit Diagram:

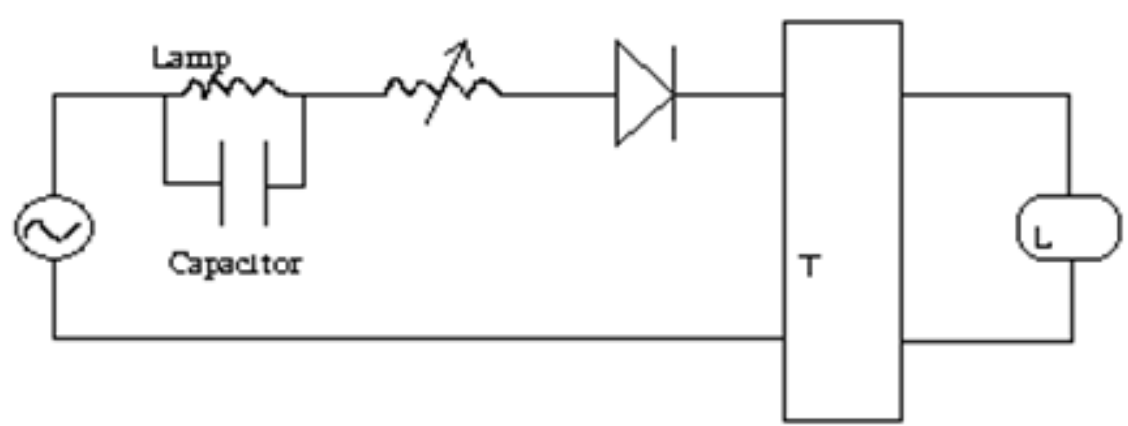

\section{T' stands for transformer \\ "L'stands for loed}

\section{EXPERIMENTAL}

The A.C supply is of $220 \mathrm{~V}-50 \mathrm{~Hz}$. It is fed to an incandescent lamp. A regulator is connected in series with the lamp. It is set at position 1 . This functions as the rheostat. As seen from the figure, the rectifier output is fed to a transformer. The capacitor is connected in parallel only with the lamp. This is quite different from the way a filter is connected. The circuit contains ripples which induce an E.M.F at the other end of the transformer. A load is connected at the transformer output. The open circuit Voltage is greater than the one with load.

Some measurements -1 .Average resistance of the diode used as rectifier $=595 \Omega$.

2. Resistance offered by the regulator when set at $l=530 \Omega$

3. Turns ratio of the transformer used $\approx 19: 1$

4. D.C resistance of the transformer L.V side $=1.5 \Omega$

5. D.C resistance of the transformer $\mathrm{H} . \mathrm{V}$ side $=79.6 \Omega$

6. The D.C voltage on the output of the transformer is of the order $\mathrm{mV}$. A maximum of $50 \mathrm{mV}$ was recorded. So it has been neglected in all cases.

7. D.C resistance of the choke $=60 \Omega$

\section{Experiment no.1}

A battery of $1.5 \mathrm{~V}$ and $3 \mathrm{~V}$ was repeatedly connected and disconnected once at H.V side and once at L.V side. The interruption caused a pulsating voltage. It allowed flux to change and hence a voltage was induced on the other side. The table is given under:-

\begin{tabular}{|l|l|l|}
\hline \multicolumn{2}{|l|}{ L.V side used as input } \\
\hline D.C voltage applied & Induced A.C voltage at output & Induced D.C voltage at output \\
\hline $1.5 \mathrm{~V}$ & $4 \mathrm{~V}$ & $1 \mathrm{~V}(10 \mathrm{~V} \text { was also noted })^{* *}$ \\
\hline $3 \mathrm{~V}$ & $10 \mathrm{~V}(67 \mathrm{~V} \text { was also noted })^{* *}$ & $1.4 \mathrm{~V}$ \\
\hline H.V side used as input & \multicolumn{2}{|l|}{} \\
\hline $1.5 \mathrm{~V}$ & $.1-.4 \mathrm{~V}^{* *}$ & $.01-.03 \mathrm{~V}$ \\
\hline $3 \mathrm{~V}$ & $.45-.5 \mathrm{~V}$ & $.05 \mathrm{~V}$ (average) \\
\hline
\end{tabular}

**The magnitude of induced voltage depends on the rate the flux changes i.e. it depends how fast the circuit is connected and broken.

This experiment was simply done to prove that if a pulsating D.C voltage can induce an E.M.F, then ripple components must so he same thing.

\section{Experiment no.2}

The circuit given in the figure was analyzed with $10 \mathrm{~W}, 15 \mathrm{~W}, 40 \mathrm{~W} \& 100 \mathrm{~W}$. The capacitors were connected in parallel one by one only with the lamp. No capacitor should be connected in parallel with the rheostat. The voltages at the transformer secondary were recorded with various loads. 


\section{Experiment no. 3}

To study the condition of minimal power consumption a separate experiment was carried out with a 10W lamp. The parallel capacitances were varied from $10 \mu \mathrm{F}$ to $42 \mu \mathrm{F}$ and the D.C current in each case was noted. During this experiment a LED was used as a load at the transformer output.

\section{OBSERVATIONS}

When experiment no.2 was tried the following graphs were plotted. These represent the no load voltages at the H.V side of the transformer with the regulator set at $l$ and the lamps with power $10 \mathrm{~W}$, $40 \mathrm{~W} \& 100 \mathrm{~W}$ respectively.
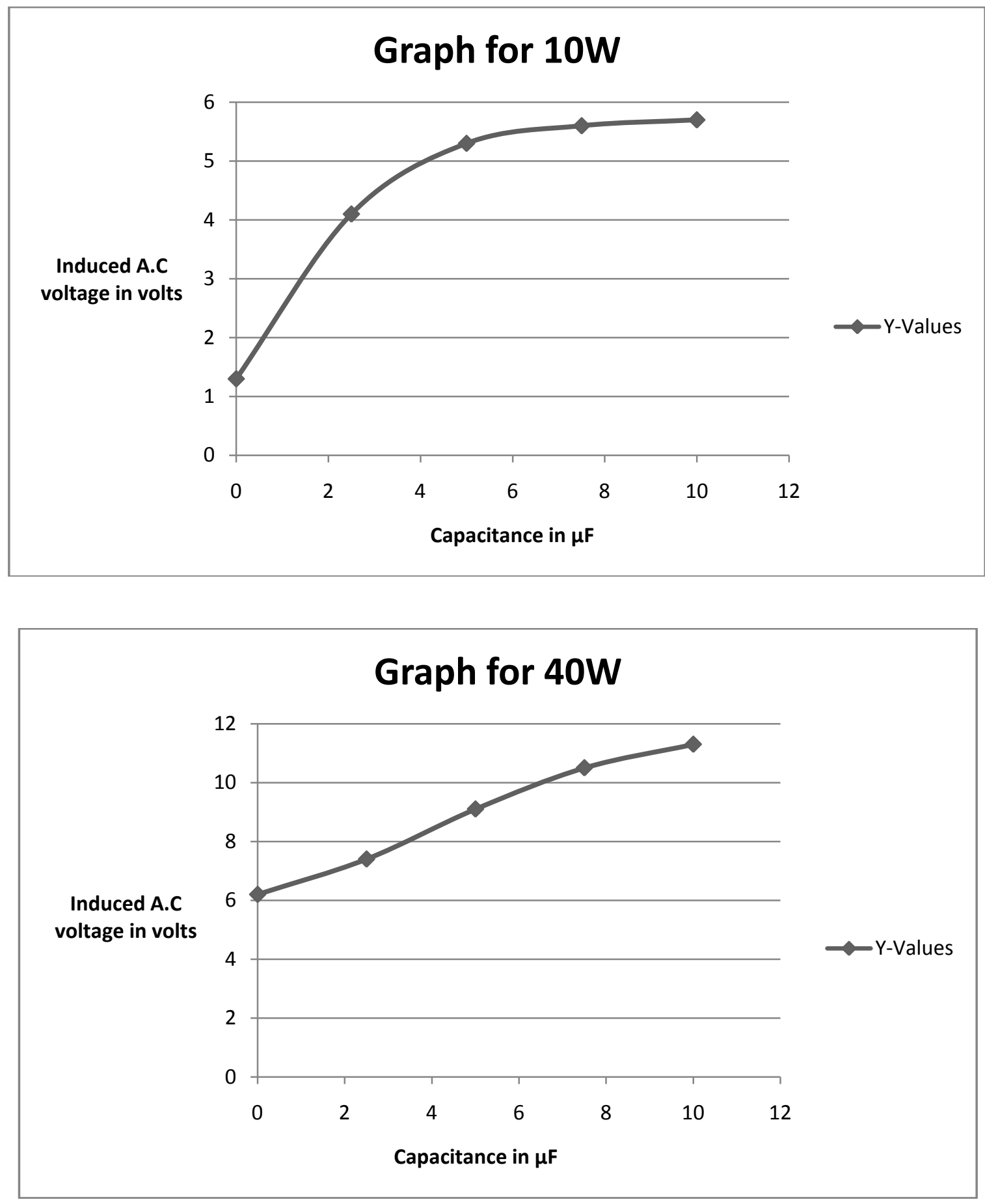


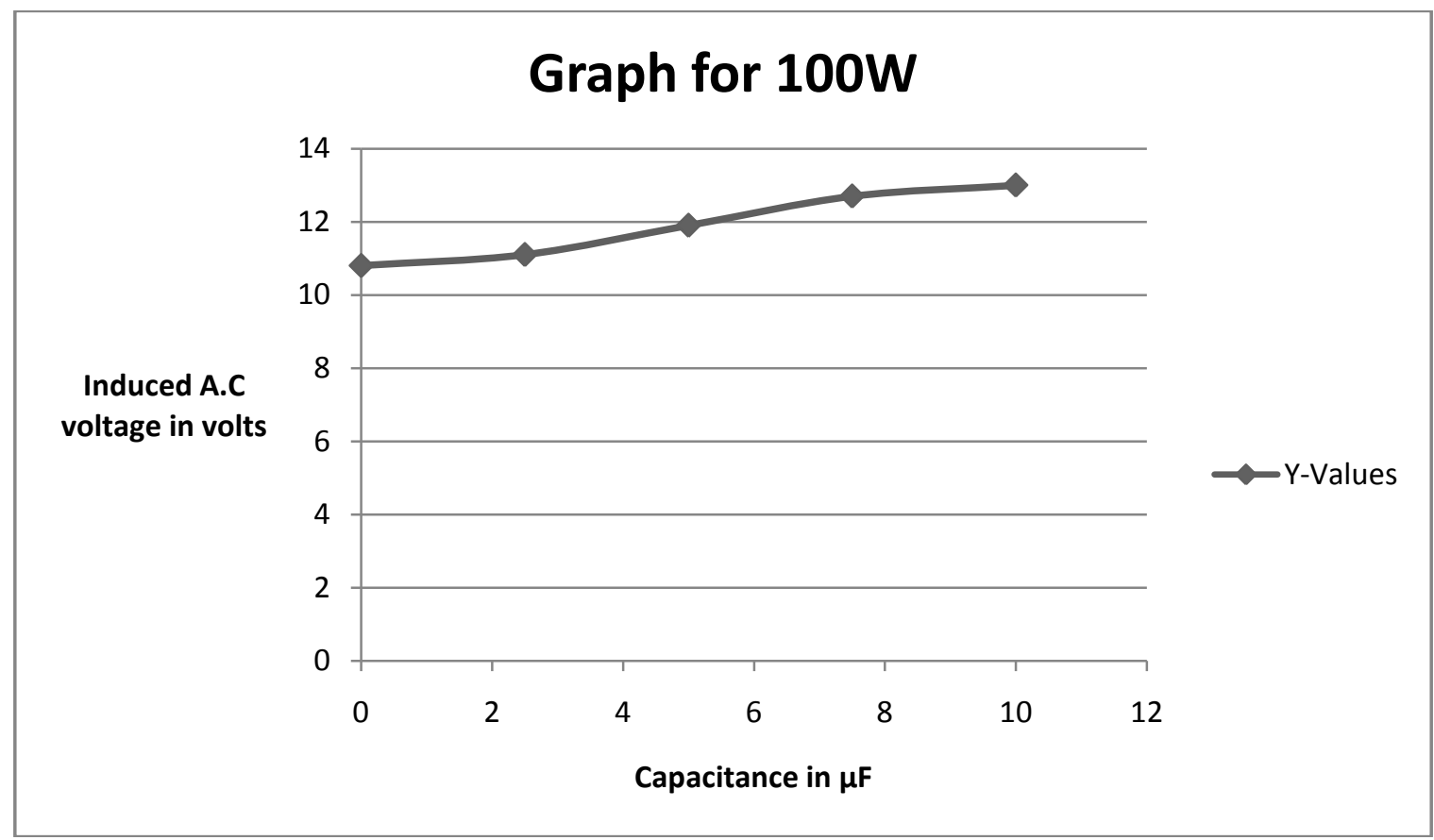

If $\Delta V / \Delta C$ is calculated for $10 \mathrm{~W}$ it is $.44 \mathrm{~V} / \mu \mathrm{F}$, for $40 \mathrm{~W}$ it increases slightly to $.51 \mathrm{~V} / \mu \mathrm{F}$ while it drops to $.22 \mathrm{~V} / \mu \mathrm{F}$ for a $100 \mathrm{~W}$ lamp. So it can be inferred that higher the wattage of the lamp, less significant is the increase in capacitance in relation to increase in voltage at the $\mathrm{H} . \mathrm{V}$ side.

Now the H.V side of the transformer was connected to a $2.7 \mathrm{~K} \Omega$ carbon film resistor and the voltage across this load was plotted.

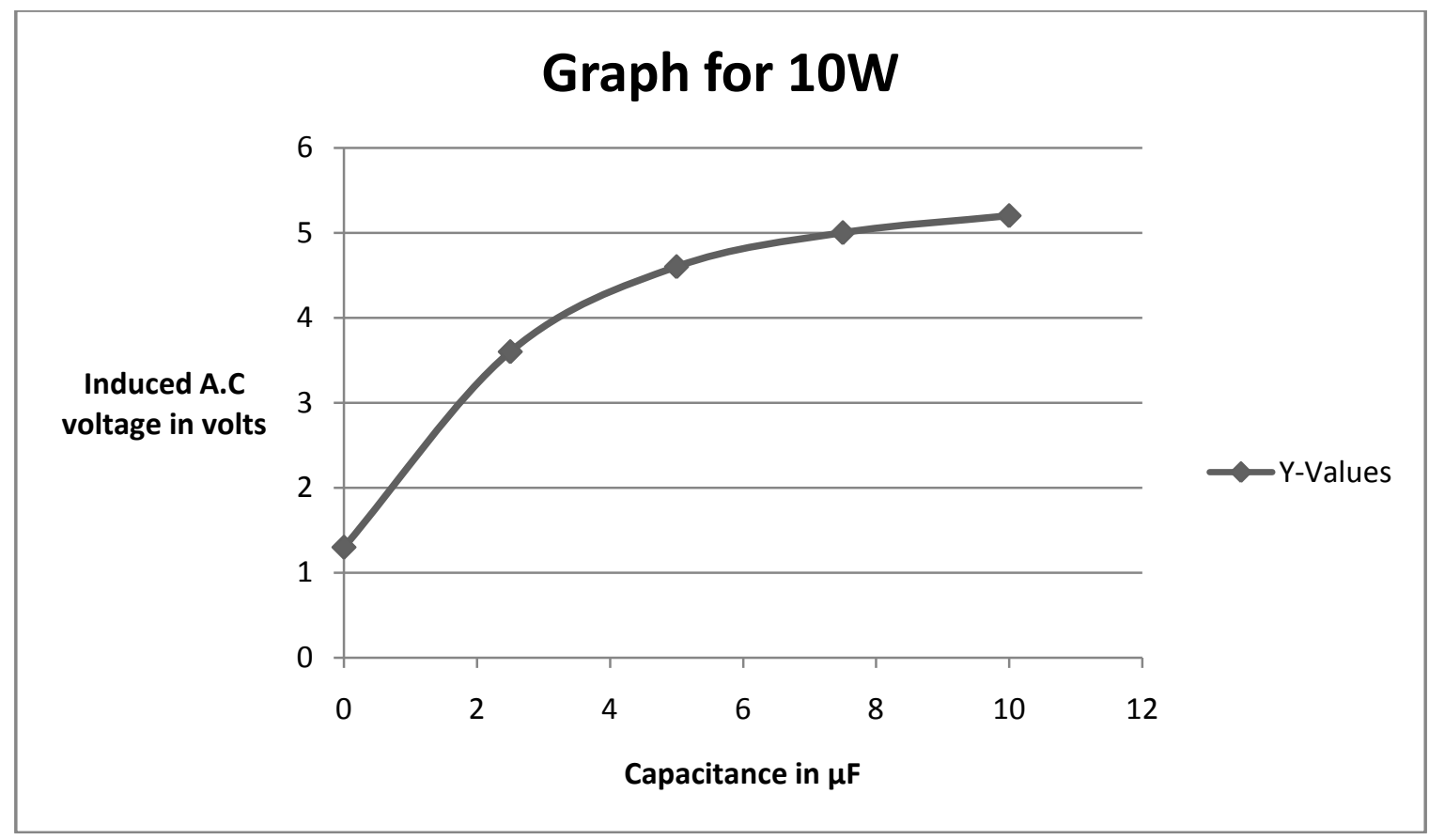



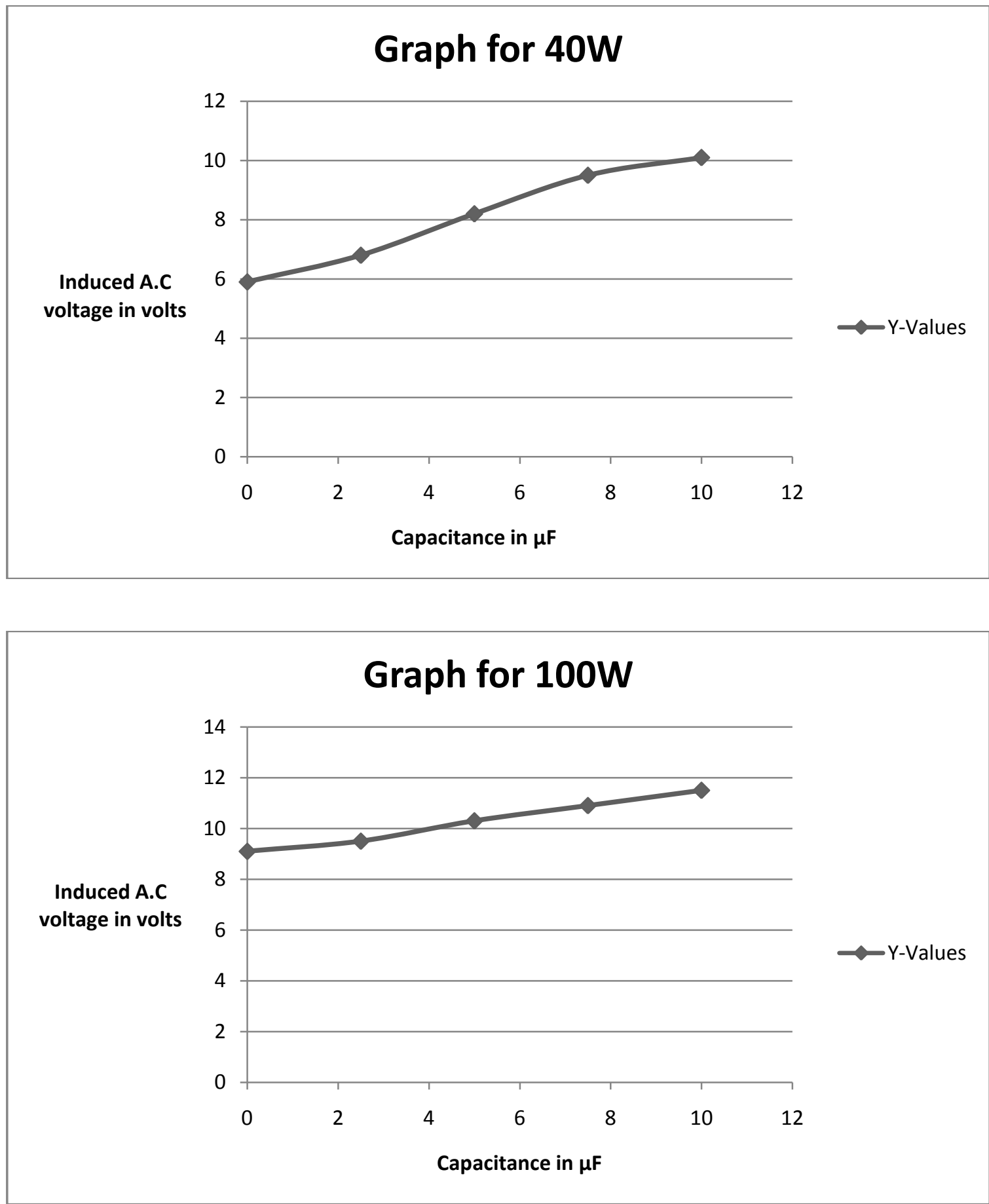

The terminal voltage decreases when load is applied. The respective values of $\Delta \mathrm{V} / \Delta \mathrm{C}$ are $.39 \mathrm{~V} / \mu \mathrm{F}$ for $10 \mathrm{~W}$, $.42 \mathrm{~V} / \mu \mathrm{F}$ in case of $40 \mathrm{~W} \& .25 \mathrm{~V} / \mu \mathrm{F}$ for $100 \mathrm{~W}$. So we get the same result as above (given in bold letters). Now the emitter base region of a transistor was used as load on the transformer H.V side. 

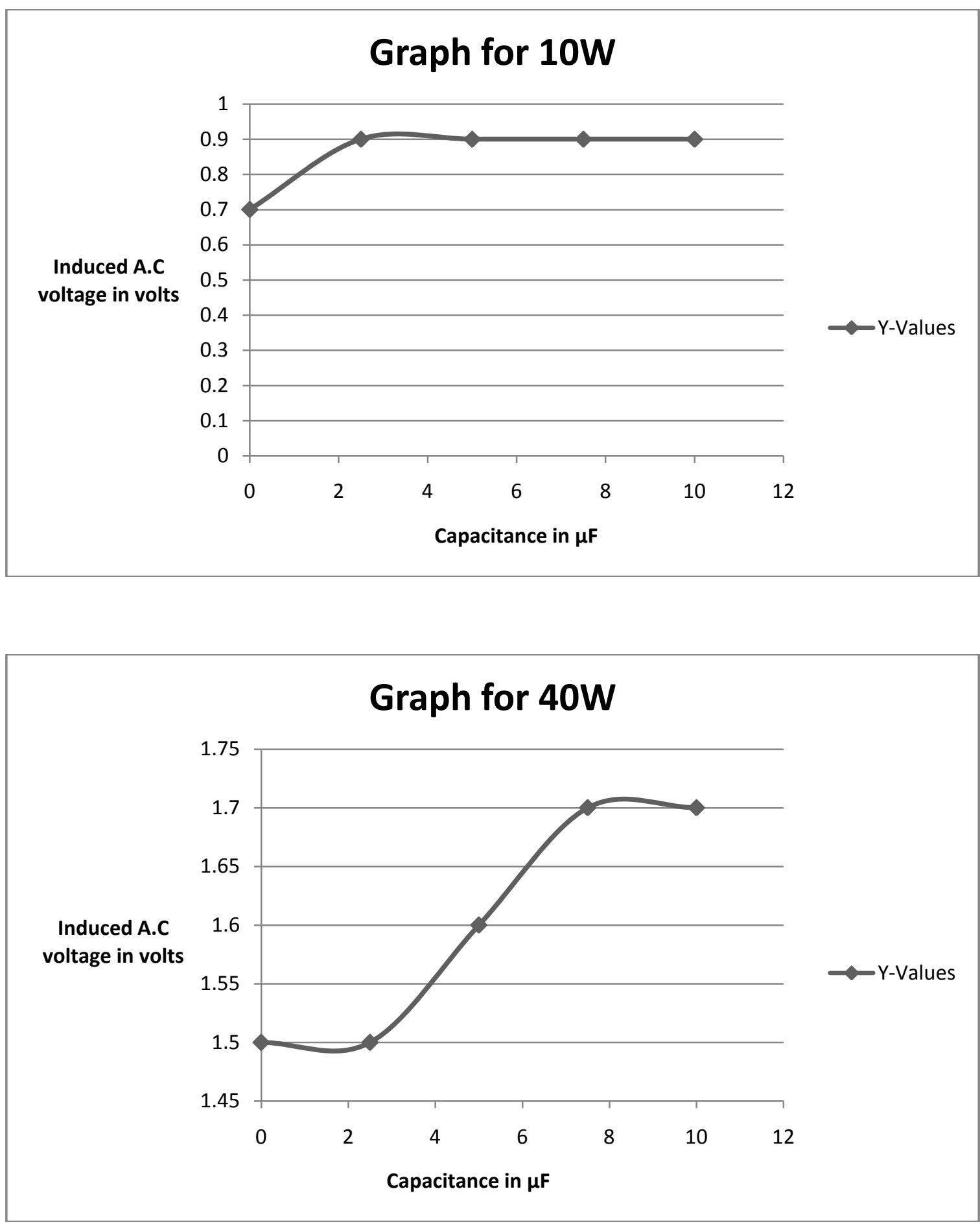


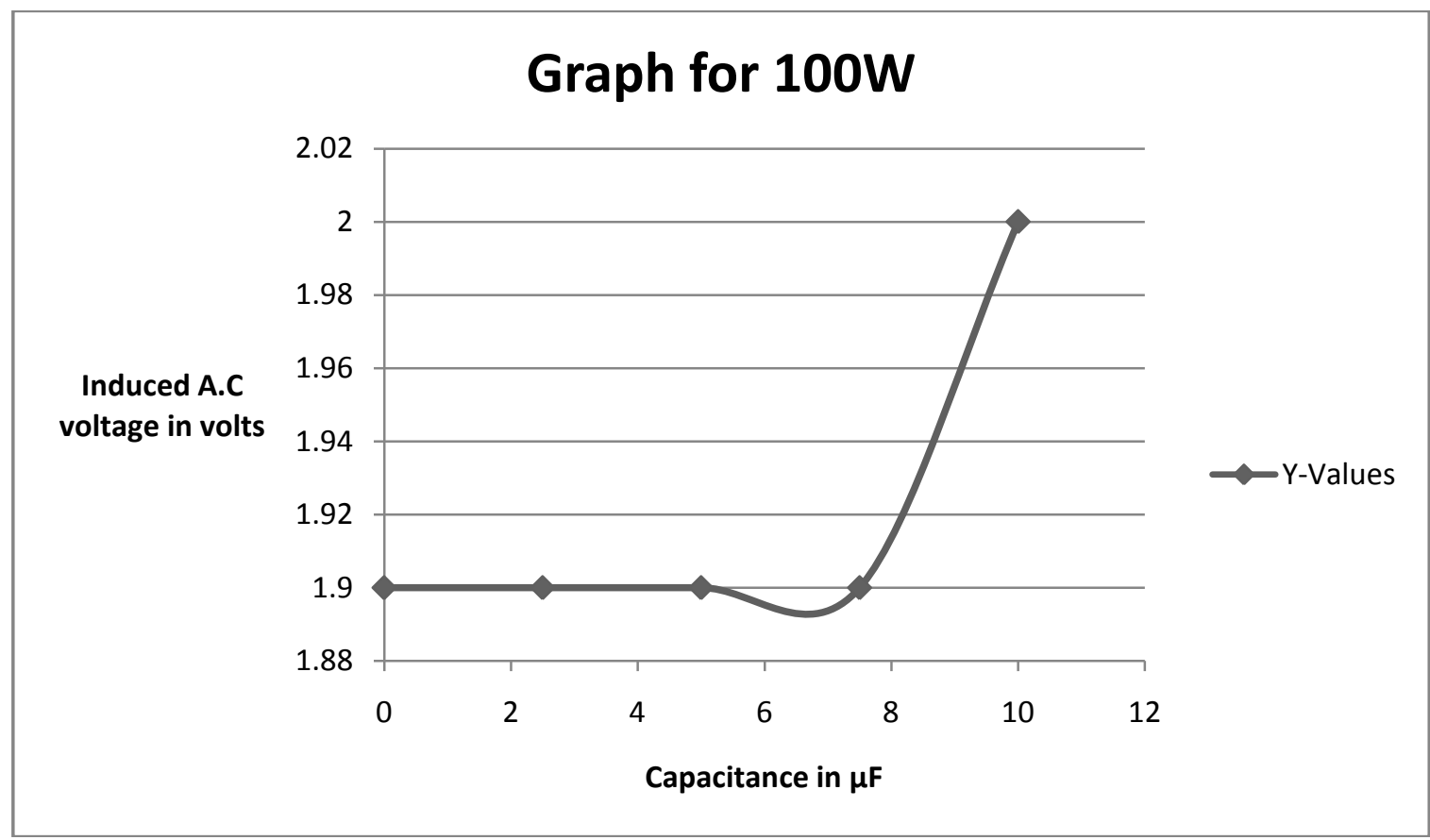

From the coordinates of the graph it will be noticed that the terminal voltage remains almost constant irrespective of the capacitance. $\Delta V / \Delta C \approx 0$.

A light emitting diode (LED) with a rated voltage of $3 \mathrm{~V}$ was used as load at the transformer H.V.

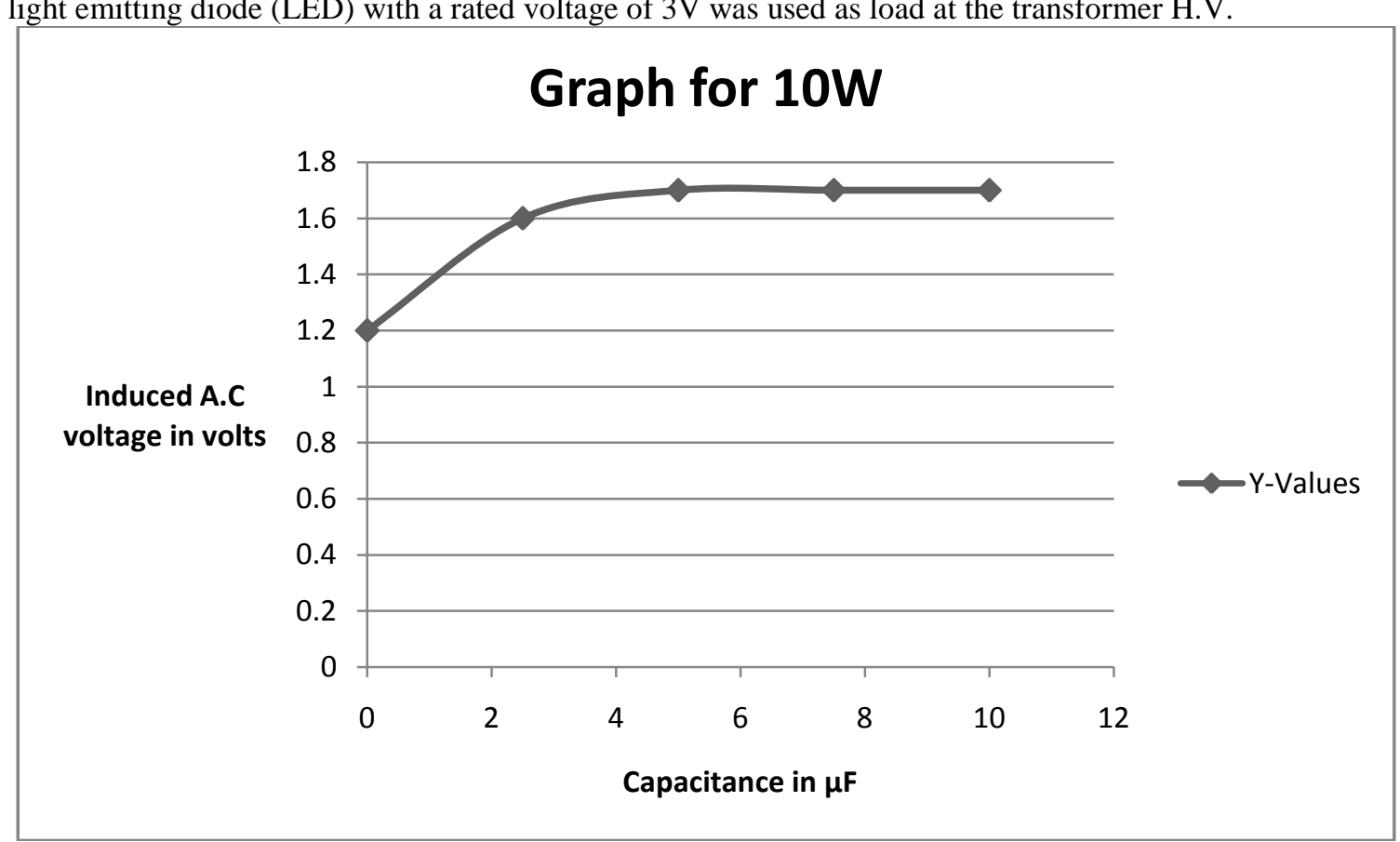



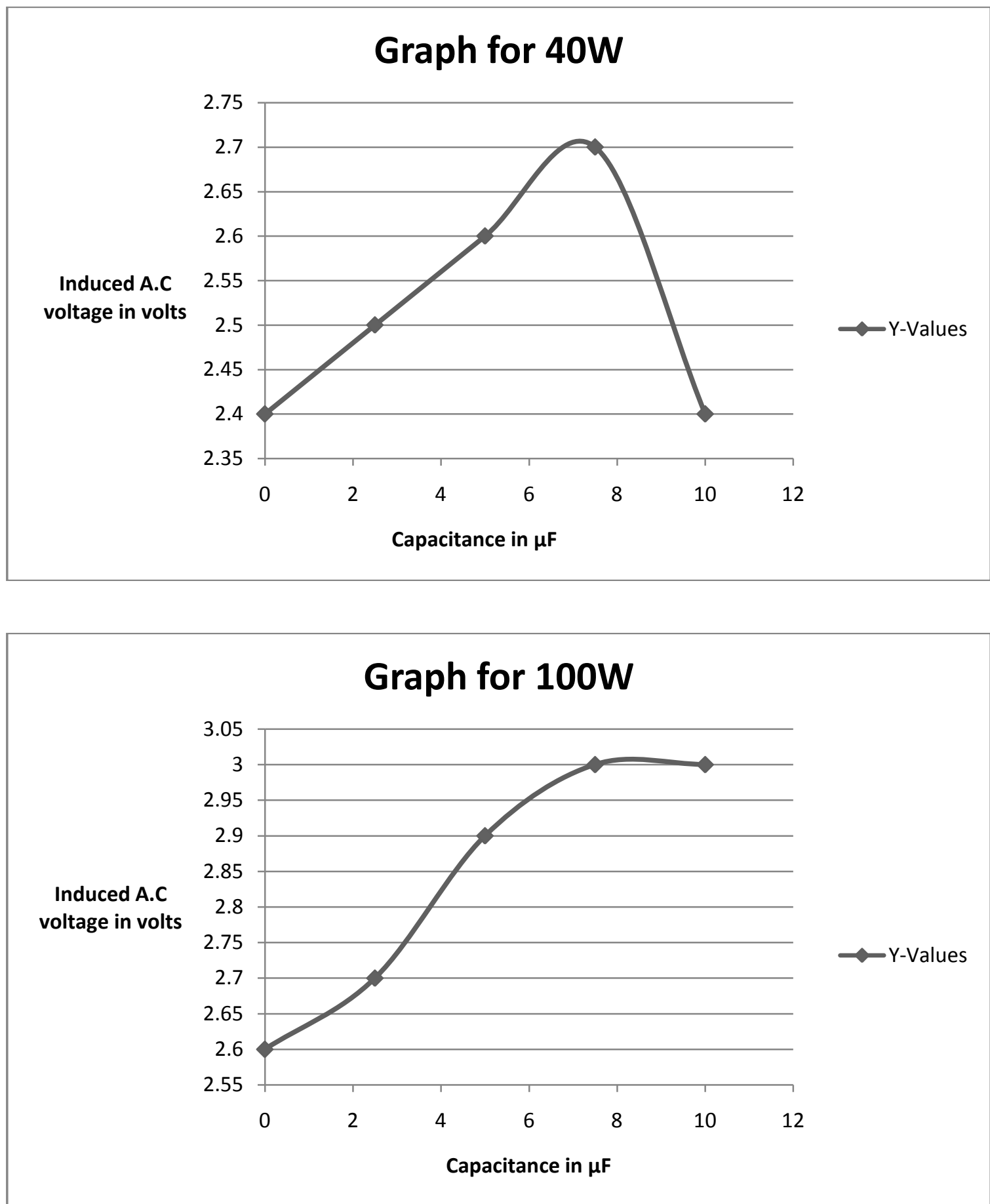

Again the change in terminal voltage per unit change in capacitance is very small.

A choke was used as load at the H.V side and the following graphs were obtained:- 

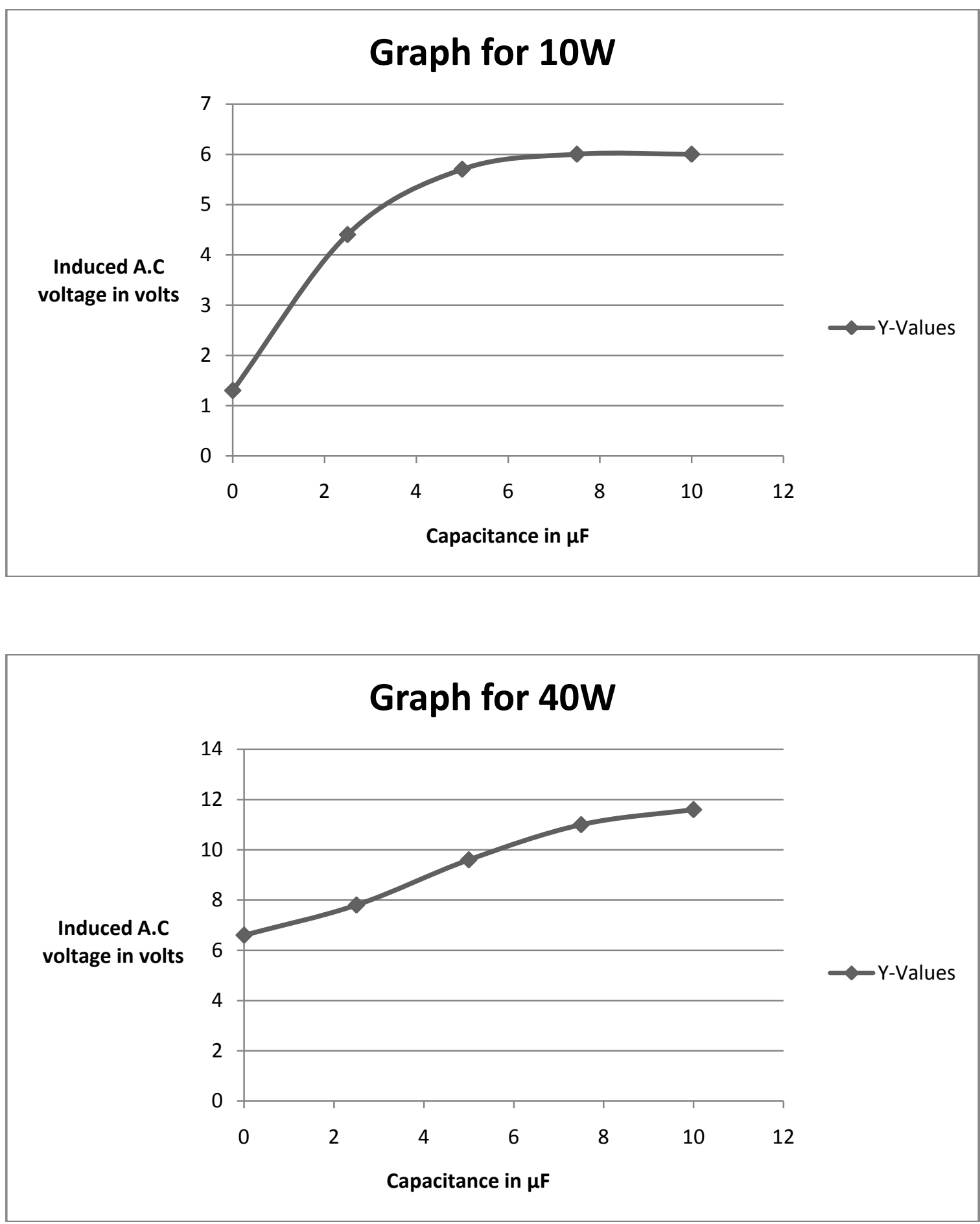


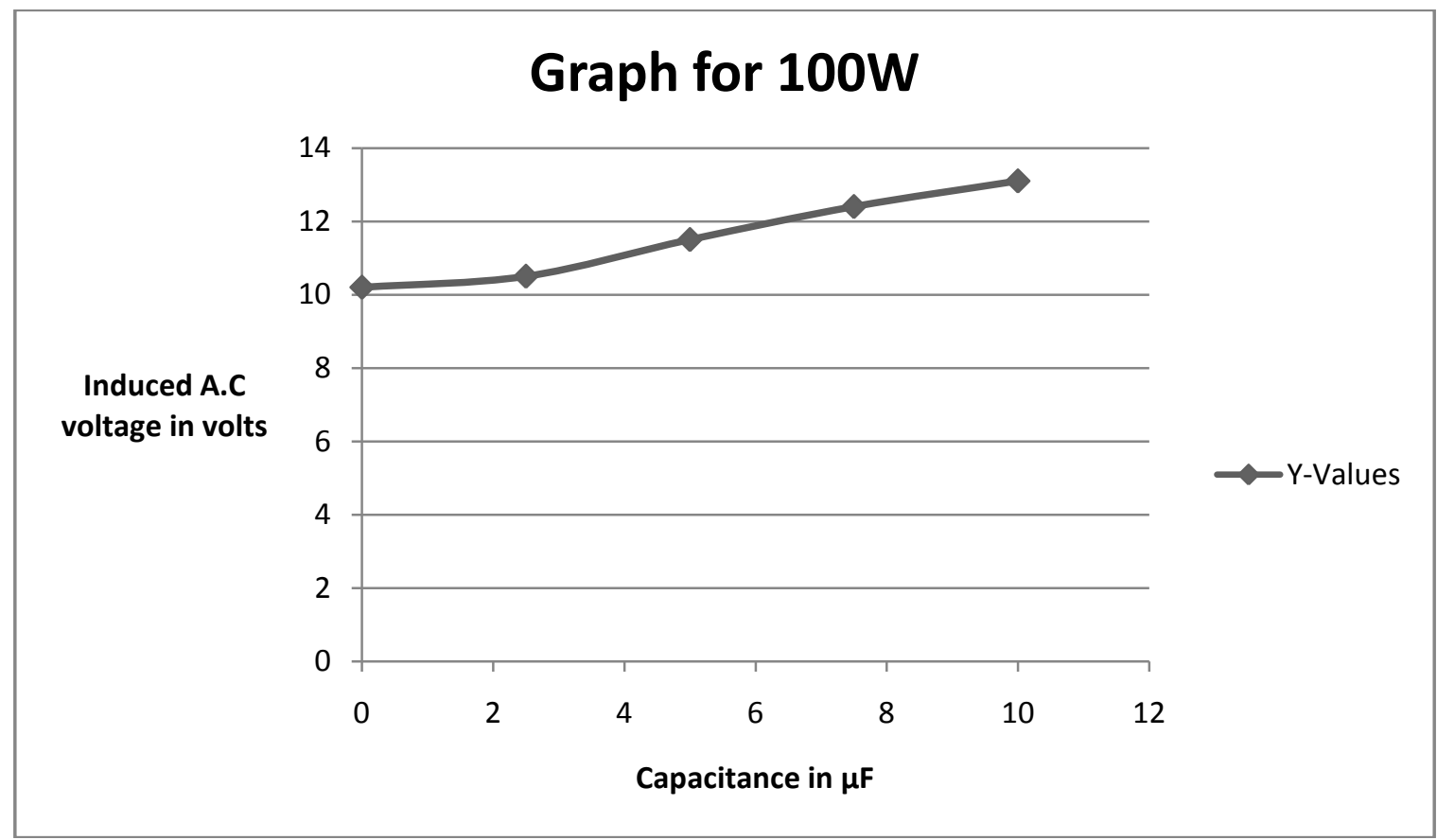

The terminal voltage in each case is greater than the no load voltages. . The respective values of $\Delta V / \Delta C$ are $.47 \mathrm{~V} / \mu \mathrm{F}$ for $10 \mathrm{~W}, .5 \mathrm{~V} / \mu \mathrm{F}$ in case of $40 \mathrm{~W} \& .29 \mathrm{~V} / \mu \mathrm{F}$ for $100 \mathrm{~W}$. These values are also greater as compared to no load conditions.

A similar experiment was performed with the L.V side used as the output. Only the no load conditions were tabulated. The table is given below:-

Table no. 2

\begin{tabular}{|c|c|c|}
\hline Wattage of lamp & Capacitance $($ in $\mu F)$ & A.C voltage at $L . V$ \\
\hline $10 \mathrm{~W}$ & \multirow[t]{3}{*}{0} & $2 \mathrm{~V}$ \\
\hline $40 \mathrm{~W}$ & & $4 \mathrm{~V}$ \\
\hline $100 \mathrm{~W}$ & & $4.6 \mathrm{~V}$ \\
\hline $10 \mathrm{~W}$ & \multirow[t]{3}{*}{2.5} & $3.7 \mathrm{~V}$ \\
\hline $40 \mathrm{~W}$ & & $4.4 \mathrm{~V}$ \\
\hline $100 \mathrm{~W}$ & & $4.7 \mathrm{~V}$ \\
\hline $10 \mathrm{~W}$ & \multirow[t]{3}{*}{5} & $3.8 \mathrm{~V}$ \\
\hline $40 \mathrm{~W}$ & & $4.7 \mathrm{~V}$ \\
\hline $100 \mathrm{~W}$ & & $4.9 \mathrm{~V}$ \\
\hline $10 \mathrm{~W}$ & \multirow[t]{3}{*}{7.5} & $3.7 \mathrm{~V}$ \\
\hline $40 \mathrm{~W}$ & & $4.8 \mathrm{~V}$ \\
\hline $100 \mathrm{~W}$ & & $5 \mathrm{~V}$ \\
\hline $10 \mathrm{~W}$ & \multirow[t]{3}{*}{10} & $3.7 \mathrm{~V}$ \\
\hline $40 \mathrm{~W}$ & & $4.8 \mathrm{~V}$ \\
\hline $100 \mathrm{~W}$ & & $5 \mathrm{~V}$ \\
\hline
\end{tabular}

From the table $\Delta V / \Delta C$ are much smaller than on the H.V side. These too decrease with increase in lamp wattage.

In case of experiment no. 3 the $10 \mathrm{~W}$ lamp and the regulator were used to control current. The measurements were taken with a parallel capacitance of 0 and $10 \mu \mathrm{F}$. The D.C current in the circuit was recorded. The H.V terminal was connected with a LED. 
Table no.3

\begin{tabular}{|c|c|c|}
\hline Wattage of lamp & $\begin{array}{ll}\mathbf{I}_{\text {D.C }} & \text { without } \\
\text { capacitor } & \\
\end{array}$ & $\begin{array}{l}\text { ID.c with capacitor } \\
(10 \mu F)\end{array}$ \\
\hline $10 \mathrm{~W}$ & $28.7 \mathrm{~mA}$ & $53.2 \mathrm{~mA}$ \\
\hline $40 \mathrm{~W}$ & $90 \mathrm{~mA}$ & $119.5 \mathrm{~mA}$ \\
\hline $100 \mathrm{~W}$ & $124.5 \mathrm{~mA}$ & $140 \mathrm{~mA}$ \\
\hline
\end{tabular}

The magnitude of current saturated after $10 \mu \mathrm{F}$. This was proved using a $10 \mathrm{~W}$ lamp and no series regulator. The following graph was obtained:-

\section{Current vs Capacitance}

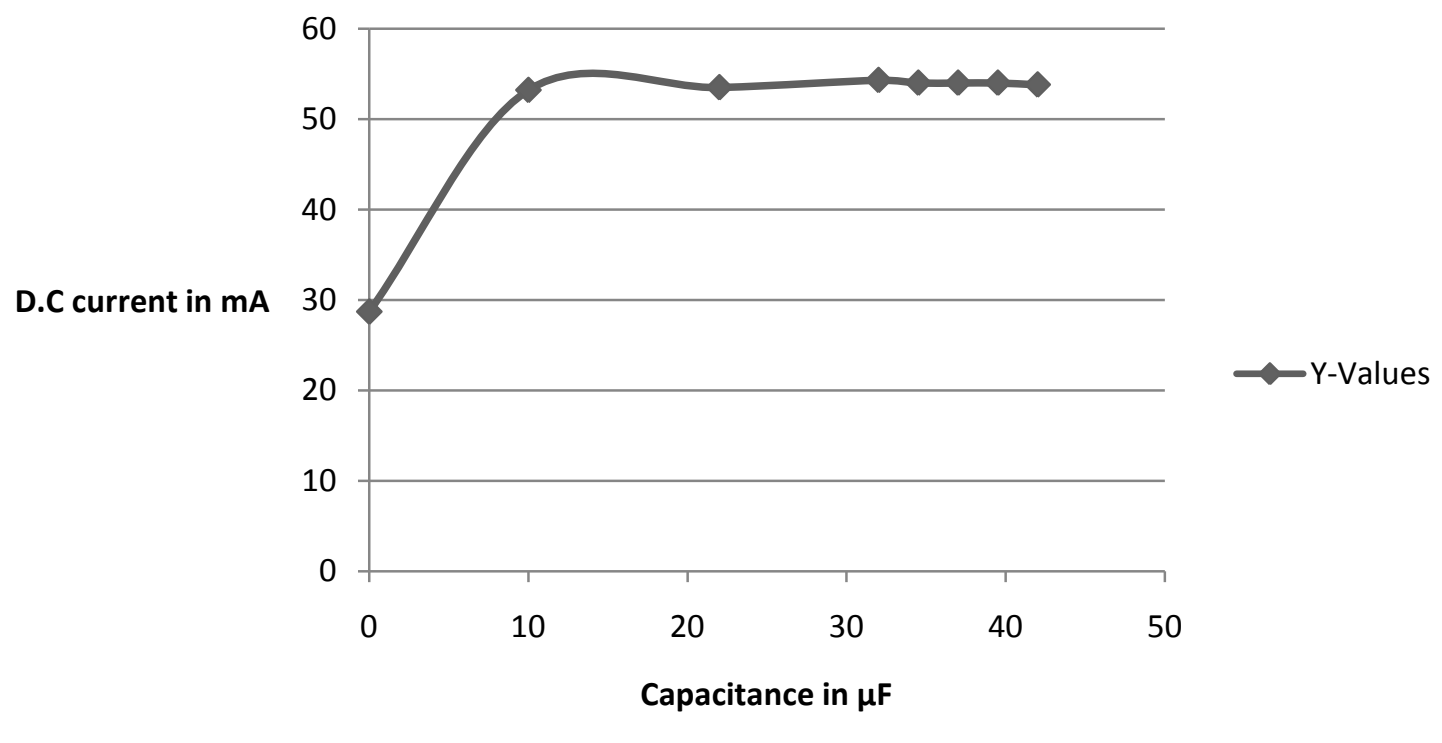

$* * *$ Capacitances between $0 \& 10 \mu \mathrm{F}$ show intermediate currents ranging from $28.7 \mathrm{~mA}$ to $53.5 \mathrm{~mA}$. At $10 \mu \mathrm{F}$ it saturates and thereafter remains constant.

During this condition an IN4007 diode was also used as a load instead of a LED on the H.V side. With a $10 \mu F$ capacitor conned in parallel the A.C voltage in the forward direction was $1 V$ while that along the reverse direction was $8.3 \mathrm{~V}$. This also proves hat a $\mathrm{p}-\mathrm{n}$ junction diode has higher resistance in the reverse direction than in the forward direction.

The output voltage of the H.V side was also amplified using a CE amplifier using a transistor. When the output voltage is taken across a $15 \mathrm{~K} \Omega$ resistor very little amplification occurs. This is due to the low frequency of the A.C signal.

\section{RESULTS AND DISCUSSIONS}

From the above experiments, tables and graphs the following results were summarized:-

a) The output of a half wave rectifier contains sufficient ripple so as to be trapped by an inductor. A capacitive filter can no provide $100 \%$ filtration.

b) The output when fed to a transformer induces E.M.F at the secondary.

c) Then magnitude of induced E.M.F depends on the load (here an incandescent lamp having a tungsten filament) in series with the half wave rectifier. Higher the power of the lamp more is the induced voltage.

d) A rheostat may be used in series with the lamp to control current in the circuit.

e) A capacitor connected in parallel only with the lamp may be used to increase the magnitude of D.C current in the circuit. However the current saturates at a certain value of capacitance and remains constant thereafter.

f) Inclusion of a capacitor also increases the magnitude of induced voltage at the secondary.

g) Value of $\Delta \mathrm{V} / \Delta \mathrm{C}$ decreases with increase in power of the lamp used. ( $\Delta \mathrm{V}$ is the change in transformer secondary voltage).

h) Regulation of the transformer is not good. Normally regulation $\approx 0$. But in this case the terminal voltage decreases to a large extent when a load is applied.

i) For an inductive load, terminal voltage is greater than the no load voltage. 
j) When the emitter base of a transistor with collector open is used as load on the output side, $\Delta \mathrm{V} / \Delta \mathrm{C} \approx 0$ i.e. there is almost no variation of terminal voltage with capacitance.

\section{CONCLUSION}

A half wave rectifier that uses only one half of the A.C cycle contains ripple that can induce an E.M.F at the transformer secondary. But as he current flows in 'jerks' and is not $100 \%$ A.C the magnitude of induced voltage is much smaller than that in case of a pure A.C circuit. The resistor that is connected in series with the rectifier controls the D.C current in the circuit. An additional rheostat my also be used. In this case the capacitor must be connected in parallel only with the load i.e. the lamp. The output voltage at the transformer secondary varies greatly with the load connected across it. Regulation of the circuit is very poor. The power consumption is quite small, about $20 \mathrm{~W}$.

\section{ACKNOWLEDGEMENTS}

I'd like to express my gratitude to Mr. P.B Nandi and Mrs. K.Nandi for constantly encouraging me. They have also provided financial support. 